\title{
A study on the determination of handgrip strength of Olympic style weightlifting athletes
}

\author{
Kenan Erdağ $1^{1 \mathrm{ABCDE}}$, Osman Tüfekçi ${ }^{2 \mathrm{ADE}}$, Mustafa Yeşeri' ${ }^{2 \mathrm{ADE}}$, Mehmet F. Yüksel ${ }^{1 \mathrm{ACD}}$, Nimet Turgut ${ }^{3 \mathrm{AC}}$, Burak E. \\ Eroğlu ${ }^{4 \mathrm{BD}}$ \\ ${ }^{1}$ Necmettin Erbakan University, Turkey \\ ${ }^{2}$ Private Farabi Hospital, Turkey \\ ${ }^{3}$ Selcuk University, Turkey \\ ${ }^{4}$ Youth and Sports Provincial Directorate, Turkey
}

Authors' Contribution: A - Study design; B - Data collection; C - Statistical analysis; D - Manuscript Preparation; E - Funds Collection.

\begin{abstract}
Purpose: $\quad$ Handgrip strength is widely accepted as a functionality parameter to assess upper extremity performance. The measurement of hand grip strength by dynamometry is a low cost, non-invasive method of simple applicability. The present study is based on the association of dominant and non-dominant handgrip strength with demographic and anthropometric characteristics; height, body weight, body mass index, upper arm length, forearm length, hand length, forearm circumference, upper arm circumference.

Material: $\quad$ The study included 70 male athletes in olympic style weightlifting (age: $18.06 \pm 2.18$, height:1.74 $\pm .06 \mathrm{~m}$, body weight: $76.09 \pm 13.04 \mathrm{~kg}$ ). A total of 70 sedentary individuals as a control group (age 18.11 \pm .18 , height:1.75 \pm .04 $\mathrm{m}$, body weight: $74.01 \pm 13.94 \mathrm{~kg}$ ) were also taken to compare study findings. The data obtained was analyzed by SPPS for Windows, version 25. Handgrip strength measurements were obtained by a Jamar dynamometer, according to the recommendations of the American Association of Hand Therapists.

Results: It was found that the values of dominant and non-dominant handgrip strength, upper arm circumference and forearm circumference length of the weightlifting athletes were higher than those of sedentary individuals $(p<.001)$. No asymmetry was observed in dominant and non-dominant handgrip strength values of the athletes and sedentary individuals. The correlations were noted between dominant and non-dominant handgrip strength values of weightlifting athletes and demographic characteristics, some anthropometric characteristics of upper extremity and weightlifting performance.

Conclusions: The variability of handgrip strength might largely be explained by some anthropometric characteristics of upper extremity.

Keywords: olympic style weightlifting, handgrip strength, dynamometry, anthropometric characteristics.
\end{abstract}

\section{Introduction}

Handgrip strength (HGS) is defined as muscular strength generated by hands. It is a general term which is employed for clinical and occupational purposes and by athletes requiring strength. Handgrip strength is the result of the maximum force that the subject is able to exert under normal biokinetic conditions through the voluntary flexion of all finger joints, thumbs, and wrists [1]. HGS tests are convenient, safe and reliable and do not require large or expensive equipment [2]. Moreover, as an indicator of general health and upper extremity strength, HGS is widely evaluated for different clinical purposes $[3,4]$. The determination of HGS is also considered to be very important while assessing performance in some sporting activities $[5,6]$, and HGS has been used as an indicator of overall muscle strength $[7,8]$.

HGS is affected by a number of factors that have been investigated in different studies. According to these studies, HGS possesses a positive correlation with age $[8,9]$, body weight, height, [10], body mass index (BMI) $[4,11,12]$, forearm circumference [13], hand size [14]

\footnotetext{
(c) Kenan Erdağı, Osman Tüfekçi, Mustafa Yeşeri, Mehmet F. Yüksel, Nimet Turgut, Burak E. Eroğlu, 2020
} doi:10.15561/20755279.2020.0303 forearm and upper arm length [15]. It was reported that owing to regular physical activities endured by athletes, anthropometric characteristics and HGS values of athletes are higher than anthropometric characteristics and HGS values of sedentary individuals [15]. It was reported that forearm circumference length of dominant and non-dominant hand in male individuals is a determinant for HGS [13]. In studies comparing dominant and nondominant HGS values, it was stated that dominant HGS value is quite higher than non-dominant HGS value [10]. It was reported that hand anthropometric characteristics and HGS values of athletes were higher than HGS values of non-athletes and that a positive correlation existed between hand anthropometric characteristics and HGS values [14].

In literature, there are limited studies regarding the assessment of correlations between HGS values and physical characteristics of upper extremity of Olympic style weightlifting athletes.

The study aims to determine HGS values of male athletes in Olympic style weightlifting athletes and sedentary individuals and to study correlations between HGS values and some length and circumference measurements of upper extremity of these groups. 


\section{Materials and methods}

\section{Participants.}

The study included two study groups: a group of male athletes in Olympic style weightlifting (MO-sW, $\mathrm{n}=70$, age: $18.06 \pm 2.18$ ) that participated in Olympic style weightlifting championships held in 2019 in Turkey (the cities of Sivas and Nevşehir) and a group of sedentary male individuals that were not into sports previously (MCG, $\mathrm{n}=70$, age $18,11 \pm .92$ ). The ethical approval to conduct the study was obtained from Medical Studies Except Medical Devices Ethics Committee in the University of Necmettin Erbakan, Meram Medical Faculty (dated 05/07/2019 and numbered 1974). All procedures followed in the study were in compliance with the ethics committee approval. All participants were informed regarding the study.

Research Design.

The study criteria for the athlete groups were as follows: Having Olympic style weightlifting trainings (snatch, clean-and-jerk, snatch or clean and jerk/hang and specific weightlifting trainings) for the last two years regularly (at least 4 days a week during this period), and having participated in national Olympic style weightlifting championships in the last year. The study criteria for the sedentary individuals were as follows: Having no sports training before. The participants in both groups with any joint problems of hand, wrist and elbow, history of fracture, musculoskeletal or neurological disorder, and deformities of upper limb were excluded from the study.

\section{Anthropometric Measurements}

A platform scale was used for weight and a tape measure was used for height and circumference measurements of the groups. All height and circumference measurements were recorded in centimeter $(\mathrm{cm})$. During the measurements of hand, hand dorsal was on the table and fingers were in full extension, the second and the fifth fingers were in adduction and thumb was in a slight extension position. The height $(\mathrm{BH})$, body weight $(\mathrm{BW})$, body mass index (BMI) values of the participants and methods and reference points to obtain anthropometric measurements of upper extremity (right arm, left arm) were listed below. For the height of the participants, the vertical distance from floor to the top point of head of the participant was measured (by Seca 769, Germany, $0.01 \mathrm{~cm}$ precision) while the participants were in upright position with naked feet and their heels were in touch each other. For the body weight measurement, the participants were asked to step on the platform scale only with their shorts and t-shirt and with naked feet. The value read on the screen of electronic scale (BC-416 MA CIID, Japan) with $0.1 \mathrm{~kg}$ precision was recorded in kilogram $(\mathrm{kg})$. BMI value was calculated by the formula: body weight/(height $)^{2}$. Upper arm length (UAL): We measured the distance from acromion to olecranon. The measurement was done while the arm was near the body in rest position [16]. Forearm length (FAL): The distance between olecranon to styloid process was measured while the elbow was at 90 degreeflexion [3]. Hand length (HL): The distance between end tip of middle finger to middle of distal line (plica carpalis distali), bordering hand and hand wrist was measured [14,
17]. Forearm circumference (FAC): While the elbow was at 90 degree-flexion and the forearm was at supination, the measurement was made from the $12 \mathrm{~cm}$ distal to olecranon without pressure [13]. Upper arm circumference (UAC): The criteria point was medial epicondyles of humerus. From this point, $10-15 \mathrm{~cm}$ or the most swollen area was marked and upper arm circumference was measured while the arm was near the body in rest position [18]. For the weightlifting performance assessment, one repetitions maximum (1RM kg) results in snatch and clean-and-jerk in weightlifting events were obtained from the online data of Turkish Weightlifting Federation. To determine dominant (right) and non-dominant hand (left), the athletes were asked which hand they use more often in daily activities requiring hand force. All participants in our study were right-handed, that is, their right hand was dominant. No participants reported ambidexterity.

\section{Handgrip Strength Measurement}

We performed all measurements in a standardized arm position for HGS tests as suggested by the American Society of Hand Therapists [19]. HGS was measured by using the standard adjustable-handle Jamar dynamometer (Asirnow Engineering Co., Los Angeles, CA, USA). The obtained HGS values were recorded in $\mathrm{kg}$. The participants were asked to sit while their shoulders were abducted and neutrally rotated, elbows were flexed at $90^{\circ}$ and the forearm and wrist were in neutral position. The participants were instructed to take two to three seconds to reach maximum effort and they were verbally encouraged during the measurements. For each strength test the scores of three successive trials were recorded for each hand. The highest HGS for each hand (dominant hand HGS, (D-HGS), non-dominant hand HGS (ND-HGS)) was used for analysis. The trials for each measurement were separated by a rest of at least one minute to minimize fatigue.

\section{Statistical Analysis}

For the analysis of the data, SPPS 25 (IBM Corp. Released 2017. IBM SPSS Statistics for Windows, Version 25.0. Armonk, NY: IBM Corp.) statistical packaged software was used. MANOVA analyses were managed to study differences in demographic variables, some anthropometric values of upper extremity, D-HGS and ND-HGS values between the groups of athletes and sedentary individuals. To compare D-HGS and ND-HGS values and some anthropometric characteristics of upper extremity of study groups, t-test for dependent groups were conducted. The correlations between D-HGS and ND-HGS values and other variables of the groups were studied by using correlation analysis.

\section{Results}

From the first MANOVA analysis, significant differences were observed in MO-sW and MCG groups, Pillai's Trace $=.46, F(6,133)=18.57$, Eta-squared $=.46$. From further analyses to find out which independent variable affects the change, it was observed that D-HGS and ND-HGS values were significantly different. No statistically significant difference was found to be present 
in demographic variables of MO-sW and MCG groups. However, it was found D-HGS and ND-HGS values of athletes were higher than D-HGS and ND-HGS values of sedentary individuals (Table 1). Moreover, it was found in the groups of athletes that maximum snatch weight was 114 kilos and maximum clean-and-jerk weight was 138 kilos.

From the other findings of following MANOVA analyses, MO-sW and MCG groups were statistically significant Pillai's Trace $=.45, \mathrm{~F}(10,129)=10.50$, Etasquared $=.45$ ). From further analyses to find out which independent variable affects the change, significant differences exist in RFAL, LFAL, RFAC, LFAC, RUAC and LUAC values of the groups. RUAL, LUAL, RHL and LHL values of the athletes and sedentary individuals were not statistically different. However, RFAL, LFAL, RFAC, LFAC, RUAC and LUAC values of the athletes were higher than those of sedentary individuals (Table 2).

Another aim of the study was to compare D-HGS and ND-HGS and some anthropometric values of upper extremity of the athletes and sedentary individuals. To do so, $t$-Test was carried out for dependent groups. The findings of the analyses showed that no significant difference existed in D-HGS and ND-HGS values of both groups $(\mathrm{p}>.05)$.

The correlations between D-HGS and ND-HGS and some anthropometric values of upper extremity of MOsW and MCG groups are shown in Table 3. A higher correlation was found in D-HGS and ND-HGS values of MO-sW. Moreover, apart from age, RUAL, LUAL, RFAL and LFAL variables of MO-sW, other variables were observed to be correlated with D-HGS and ND-HGS. A high correlation was found between D-HGS and NDHGS of MCG. Furthermore, D-HGS and ND-HGS values were correlated with RFAC and LFAC variables of MCG.

\section{Discussion}

No statistical difference was observed in age, BH, BW and BMI variables of the athletes and sedentary individuals in the study. However, it was noted that (right-left) FAL, (right-left) FAC, (right-left) UAC measurements of upper extremity and HGS values of MO-sW were higher than those of MCG. Upper extremity anthropometry and HGS differences observed in weightlifting athletes and sedentary individuals are considered likely to be due to regular weightlifting trainings of the athletes.

HGS is affected by a number of factors that have been investigated in different studies. According to these studies, HGS possesses a positive correlation with age, $\mathrm{BW}, \mathrm{BH}, \mathrm{BMI}$ and some anthropometric characteristics of upper extremity. Fallahi and Jadidian [14] studied the correlations between HGS and hand dimensions, hand shape and some hand anthropometric characteristics of male athletes (basketball, handball, volleyball players, wrestlers) and they reported that HGS, HL, palm width, finger length, FAL, FAC and wrist circumference values of the athletes were higher than those of non-athletes. It was reported that height, HL, hand width, total arm length, right-left HGS values of cricketers are higher than those of sedentary individuals and the differences might be owing to the regular physical exercises of the athletes [15]. It was stated that D-HGS and ND-HGS values of athletes participating in international tennis tournaments are higher than HGS values of sedentary individuals [20]. In a study on anthropometric characteristics and HGS values of male elite rock climbers (the highest climbing grades), recreational climbers (a low climbing grade category) and non-climbers (had not previously done any rock climbing), it was declared that HGS values of elite rock climbers are higher than HGS values of the other two groups [21]. Franchini et al. [22] assessed upper extremity anthropometry and HGS values of elite and non-elite

Table 1. Demographic, D-HGS and ND-HGS values of MO-sW and MCG groups.

\begin{tabular}{|c|c|c|c|c|c|}
\hline Characteristics & $\begin{array}{l}\text { Groups } \\
(M O-s W \text { n=70, MCG n=70) }\end{array}$ & Mean & SD & $\mathbf{F}$ & Eta-squared \\
\hline \multirow{2}{*}{ Age (year) } & MO-sW & 18.06 & 2.18 & \multirow{2}{*}{.041} & \multirow{2}{*}{.000} \\
\hline & MCG & 18.11 & .92 & & \\
\hline \multirow{2}{*}{$\mathrm{BH}(\mathrm{cm})$} & MO-sW & 1.74 & .06 & \multirow{2}{*}{.289} & \multirow{2}{*}{.002} \\
\hline & MCG & 1.75 & .04 & & \\
\hline \multirow{2}{*}{ BW (kg) } & MO-sW & 76.09 & 13.04 & \multirow{2}{*}{.824} & \multirow{2}{*}{.006} \\
\hline & MCG & 74.01 & 13.94 & & \\
\hline \multirow{2}{*}{ BMI $\left(\mathrm{kg} / \mathrm{m}^{2}\right)$} & MO-sW & 24.78 & 3.46 & \multirow{2}{*}{1.687} & \multirow{2}{*}{.012} \\
\hline & MCG & 23.97 & 3.84 & & \\
\hline \multirow{2}{*}{ D-HGS (kg) } & MO-sW & 54.81 & 10.83 & \multirow{2}{*}{$93.80 * * *$} & \multirow{2}{*}{.405} \\
\hline & MCG & 40.37 & 6.19 & & \\
\hline \multirow{2}{*}{ ND-HGS (kg) } & MO-sW & 53.71 & 10.27 & \multirow{2}{*}{$84.63 * * *$} & \multirow{2}{*}{.380} \\
\hline & MCG & 39.69 & 7.56 & & \\
\hline
\end{tabular}

Note: MO-sW: Male athletes in olympic style weightlifting, (MCG: Male sedentary control group, BH: Height, BW: Body weight, BMI: Body mass index, D-HGS: Dominant handgrip strength, ND- HGS: Non-dominant handgrip strength. $* * * \mathrm{p}<.001$ 
Table 2. The comparison of some anthropometric values of upper extremity of athletes and sedentary individuals

\begin{tabular}{|c|c|c|c|c|c|}
\hline Variables & $\begin{array}{l}\text { Groups } \\
(\mathrm{MO}-\mathrm{sW} \mathrm{n}=70, \mathrm{MCG} n=70)\end{array}$ & Mean & SD & $\mathbf{F}$ & Eta-squared \\
\hline \multirow{2}{*}{ RUAL (cm) } & MO-sW & 36.25 & 3.29 & \multirow{2}{*}{.638} & \multirow{2}{*}{.005} \\
\hline & MCG & 36.64 & 2.46 & & \\
\hline \multirow{2}{*}{ LUAL (cm) } & MO-sW & 36.15 & 3.27 & \multirow{2}{*}{.682} & \multirow{2}{*}{.005} \\
\hline & MCG & 36.55 & 2.51 & & \\
\hline \multirow{2}{*}{ RFAL (cm) } & MO-sW & 28.95 & 2.15 & \multirow{2}{*}{$8.845^{* *}$} & \multirow{2}{*}{.060} \\
\hline & MCG & 27.91 & 1.98 & & \\
\hline \multirow{2}{*}{ LFAL (cm) } & MO-sW & 29.05 & 2.48 & \multirow{2}{*}{$10.857^{* *}$} & \multirow{2}{*}{.073} \\
\hline & MCG & 27.82 & 1.90 & & \\
\hline \multirow{2}{*}{$\mathrm{RHL}(\mathrm{cm})$} & MO-sW & 19.23 & 1.13 & \multirow{2}{*}{1.338} & \multirow{2}{*}{.010} \\
\hline & MCG & 18.96 & 1.60 & & \\
\hline \multirow{2}{*}{$\mathrm{LHL}(\mathrm{cm})$} & MO-sW & 19.24 & 1.16 & \multirow{2}{*}{1.101} & \multirow{2}{*}{.008} \\
\hline & MCG & 18.99 & 1.61 & & \\
\hline \multirow{2}{*}{ RFAC (cm) } & MO-sW & 28.26 & 2.97 & \multirow{2}{*}{$89.965 * * *$} & \multirow{2}{*}{.395} \\
\hline & MCG & 24.15 & 2.06 & & \\
\hline \multirow{2}{*}{ LFAC (cm) } & MO-sW & 28.20 & 2.85 & \multirow{2}{*}{$96.202 * * *$} & \multirow{2}{*}{.411} \\
\hline & MCG & 24.15 & 1.95 & & \\
\hline \multirow{2}{*}{ RUAC (cm) } & MO-sW & 32.68 & 4.22 & \multirow{2}{*}{$47.182 * * *$} & \multirow{2}{*}{.255} \\
\hline & MCG & 28.28 & 3.30 & & \\
\hline \multirow{2}{*}{ LUAC (cm) } & MO-sW & 32.50 & 4.23 & \multirow{2}{*}{$44.109 * * *$} & \multirow{2}{*}{.242} \\
\hline & MCG & 28.22 & 3.31 & & \\
\hline
\end{tabular}

Note: MO-sW: Male athletes in Olympic style weightlifting, (MCG: Male sedentary control group, RUAL, LUAL: (Right, Left upper arm length), RFAL, LFAL: (Right, Left forearm length), RHL, LHL: (Right, Left hand length), RFAC, LFAC: (Right, Left forearm circumference), RUAC, LUAC: (Right, Left upper arm circumference). ${ }^{* *} p<.01, * * * p<.001$

Table 3. The correlations between D-HGS, ND-HGS and some anthropometric values of upper extremity of the groups.

\begin{tabular}{|c|c|c|c|c|}
\hline \multirow[t]{2}{*}{ Variables } & $\begin{array}{l}\text { MO-sW } \\
(n=70)\end{array}$ & & \multicolumn{2}{|l|}{$\begin{array}{l}\text { MCG } \\
(n=70)\end{array}$} \\
\hline & D-HGS & ND- HGS & D-HGS & ND- HGS \\
\hline D-HGS & 1 & $.824^{* * *}$ & 1 & $.794^{* * *}$ \\
\hline ND-HGS & $.824^{* * *}$ & 1 & $.794^{* * *}$ & 1 \\
\hline Age & .096 & .102 & .081 & .007 \\
\hline $\mathrm{BH}(\mathrm{cm})$ & $.342^{* *}$ & $.337^{* *}$ & .231 & .178 \\
\hline $\mathrm{BW}(\mathrm{kg})$ & $.464^{* * *}$ & $.505^{* * *}$ & .086 & .059 \\
\hline BMI $\left(\mathrm{kg} / \mathrm{m}^{2}\right)$ & $.373^{* *}$ & $.422^{* * *}$ & .027 & .015 \\
\hline Snatch (kg) & $.595^{* * *}$ & $.641^{* * *}$ & - & - \\
\hline Clean and jerk (kg) & $.594^{* * *}$ & $.637^{* * *}$ & - & - \\
\hline RUAL (cm) & -.018 & .055 & .139 & .141 \\
\hline LUAL (cm) & .002 & .068 & .114 & .099 \\
\hline RFAL (cm) & .041 & .114 & .220 & .172 \\
\hline LFAL (cm) & .034 & .049 & .203 & .185 \\
\hline $\mathrm{RHL}(\mathrm{cm})$ & $.311^{* *}$ & $.363^{* *}$ & .208 & .027 \\
\hline $\mathrm{LHL}(\mathrm{cm})$ & $.344^{* *}$ & $.335^{* *}$ & .180 & .006 \\
\hline $\operatorname{RFAC}(\mathrm{cm})$ & $.450^{* * *}$ & $.553^{* * *}$ & $.280^{*}$ & $.245^{*}$ \\
\hline LFAC $(\mathrm{cm})$ & $.452^{* *}$ & $.554^{* *}$ & $.241^{*}$ & $.238^{*}$ \\
\hline $\operatorname{RUAC}(\mathrm{cm})$ & $.335^{* *}$ & $.439^{* * *}$ & .070 & .135 \\
\hline LUAC (cm) & $.342^{* *}$ & $.433^{* * *}$ & .078 & .148 \\
\hline
\end{tabular}

Note: MO-sW: Male athletes in Olympic style weightlifting, MCG: Male sedentary control group, D-HGS: Dominant handgrip strength, ND-HGS: Non-dominant handgrip strength, BH: Height, BW: Body weight, BMI: Body mass index, RUAL, LUAL: (Right, Left upper arm length), RFAL, LFAL: (Right, Left forearm length), RHL, LHL: (Right, Left hand length), RFAC, LFAC: (Right, Left forearm circumference), RUAC, LUAC: (Right, Left upper arm circumference). ${ }^{*} p<.05,{ }^{*} p<.01$, $* * * p<.001$ 
judo athletes and they reported that anthropometric measurements of elite judo athletes are higher than those of non-elite judo athletes, whereas no statistical difference exists in HGS values of elite and non-elite judo athletes.

In literature, there are limited studies regarding the correlations between HGS values and anthropometric characteristics of upper extremity of weightlifting athletes. Furthermore, most of these studies were into the comparison of HGS values of weightlifting athletes and athletes in other types of sports. We were not able to find any studies regarding HGS values of female weightlifting athletes. In a study on physical and physiological characteristics of judo and weightlifting athletes, it was reported that HGS values of weightlifting athletes were not statistically different from HGS values of judo athletes [23]. Fry et al. [5] studied physical performance of elite, non-elite junior Olympic style weightlifting athletes aged $14.8 \pm 2.3$ and reported that HGS values of elite junior athletes competing in world weightlifting championships and breaking world records were $52.5 \pm 8.1 \mathrm{~kg}$, whereas HGS values of non-elite junior athletes were $48.1 \pm 13.6$ kg. Akkus [24] studied the correlations between snatch and clean-and-jerk records and anthropometric characteristics, physiological variables and bio-motor abilities of elitelevel Turkish weightlifting athletes and they expressed that right HGS values of the athletes were $55.90 \pm 10.93$ $\mathrm{kg}$ and left HGS values were $50.89 \pm 9.54 \mathrm{~kg}$.

It was observed in our study that HGS values of the weightlifting athletes in our study were higher than Fallahi and Jadidian [14] (volleyball, handball, basketball players), Koley et al. [15] (cricket players), Singla and Hussain [25] (adolescent and adult cricket players), Franchini et al. [22] (judo athletes), Gerodimos [26] (prepubertal, adolescent basketball players), Sarıtaş et al. [23] (weightlifting and judo athletes), Fry et al. [5] (weightlifting athletes), Grant et al. [21] (climbers). We consider that HGS differences observed in groups might also be caused by age, BH, BW, BMI, upper extremity anthropometry characteristics, HGS measurement methods as well as the type of sports and different kinds of trainings that affect handgrip strength. Moreover, it was observed that HGS values of adult basketball players in the study of Gerodimos [26] are higher than HGS values of weightlifting athletes in our study. We are of the opinion that these differences observed in HGS values might be correlated with the fact that age, $\mathrm{BH}, \mathrm{BW}$ and training year data of the basketball players are higher than those of athletes in our study. Although UAC and FAC values of the tennis players in the study of Gojanovic et al. [20] were lower than those of the weightlifting athletes in our study, it was observed that their D-HGS were higher than D-HGS of the weightlifting athletes. We estimate that the difference might be due to age range of the groups. It was observed that right HGS of the weightlifting athletes in the study of Akkus [24] was higher than right HGS values of the athletes in our study. It is considered that the difference might be closely correlated with age, BW, UAC differences along with weightlifting performances.

Depending on the use of dominant hand, right HGS and left HGS might be different. In our study, it was known that all participants of the study, both the athletes and the sedentary individuals, preferred their right hand as dominant one. However, when we compared D-HGS and ND-HGS values of all participants, no asymmetry was observed between dominant and non-dominant hand. Anakwe et al. [13] reported that HGS values of healthy males are higher than HGS values of females. What's more, the authors also reported that in both groups D-HGS values are higher than ND-HGS values. In another study including healthy males and females, Li et al. [27] stated that FAC measures of dominant hand of healthy males and females were bigger than FAC measures of non-dominant hand, as a result of this, D-HGS values are higher than NDHGS. It was explained that tennis players participating in international and national tournaments have higher D-HGS values than ND-HGS values and the resulting higher HGS values might be correlated with asymmetric tennis trainings [20]. In their study including fencing athletes, Margonato et al. [28] reported that D-HGS of the athletes is higher than ND-HGS. The researchers commented that D-HGS and ND-HGS differences observed might be due to asymmetric trainings in fencing sport. In a study on the evaluation of HGS values of male handball players, it was declared that D-HGS and NDHGS values of the athletes are much higher than ND-HGS values [29]. The researchers reached to the conclusion that the reasons for D-HGS and ND-HGS asymmetry in these athletes might be caused by the fact that they prefer their dominant hand during trainings and competitions. In another study on HGS values of male basketball players at different ages (prepubertal, adolescent and adult), it was found no statistical difference exists in D-HGS and ND-HGS values of the participants [26]. The researcher stated that the reason for the symmetry in D-HGS and ND-HGS values of the players might be owing to the fact that in basketball, players use both hands continually and simultaneously.

Olympic style weightlifting is a type of symmetric sports. From the view that the load on each arm is the same during snatch and clean-and-jerk movements, we consider that D-HGS and ND-HGS values of the weightlifting athletes in our study are equal. However, asymmetric developments occur slowly and depend on different factors (technical level and training experience of the athlete, the lack of specific exercise in related sport), we think that the determination of D-HGS and NDHGS values at certain intervals to detect any asymmetric development and the prevention of any such developments through specific exercises might be useful for the body health and athletic performance of the athletes.

In a study comparing the correlation between HGS values and anthropometric and demographic data, it was reported that D-HGS and ND-HGS values are not correlated with age, whereas the values are positively and moderately correlated with height, body weight, hand length and forearm length. Also, it was stated that both D-HGS and ND-HGS values are positively and highly correlated with hand width and FAC [30]. In another 
study including sedentary individuals, Kallman et al. [8] found that HGS increases into the fourth decade of life and declines thereafter at an accelerating rate. They also noted that muscle mass and FAC decrease by age and summed FAC is strongly correlated with HGS. Balogun et al. [11] reported that a positive correlation exists in HGS and body weight and height independently of age. Nonetheless, the researchers also noted that during the first two decades of life, HGS is positively correlated with Quetelet index. In another study assessing the correlations of HGS with hand dimensions, hand shape and some hand anthropometric characteristics of male athletes and non-athletes, it was reported that HGS is positively correlated with body height, body mass, lean body mass, BMI of athletes and with body mass, lean body mass, body fat and BMI of non-athletes [14]. Moreover, the authors of the study also declared that after controlling body mass, all hand anthropometric characteristics except thumb length, hand shape, middle finger length and FAC are significantly correlated with HGS in grip athletes, but not in non-athletes, except for FAC. Yıldırım et al. [29] reported that right HGS of handball players is correlated with biceps circumference, FAC, hand wrist circumference and upper arm length. Singla and Hussain [25] noted that HGS values of adolescent cricket players are not correlated with age, height, body weight and BMI, however, left HGS values of adult cricket players are significantly correlated with height, body weight and BMI. In another study including cricket players, Koley et al. [15] stated that right HGS values of the players are positively and significantly correlated with body weight, BMI, HL, hand width and FAL values. Aydos et al. [31] studied HGS values of weightlifting athletes, athletes in individual and team sports and they expressed that they didn't notice a correlation of HGS with body weight of weightlifting athletes however HGS values of other athletes doing individual or team sports are correlated with body weight. Erdağ ${ }_{1}$ et al. [32] reported that Olympic style weightlifting training positively increased the finger strength of weightlifting athletes. In another study conducted with elite Turkish weightlifting athletes, Akkuş [24] stated that as body weight of weightlifting athletes increases, HGS values also reach at higher values. The author also noted that wrist diameter, UAL and FAL positively correlate with weightlifting performance (snatch and clean-and-jerk).

In our study, it was observed that D-HGS and NDHGS values of athletes and sedentary individuals are highly correlated. Moreover, it was found that D-HGS and ND-HGS values of athletes are correlated with $\mathrm{BH}, \mathrm{BW}$, BMI, right and left arm HL, FAC, UAC and weightlifting performance. It was also found that D-HGS and ND-HGS values of sedentary individuals and right-left arm FAC are correlated.

There were various limitations in our study. Especially, during the study period, we had an insufficient number of female Olympic style weightlifting athletes participating in national championships. That's why, the study was conducted with male weightlifters only and the inclusion of female athletes would generalize our study. Moreover, we might state that more studies with more samples might be needed in further studies with Olympic style weightlifting athletes.

Our study proved that D-HGS and ND-HGS values of weightlifting athletes are higher than those of sedentary individuals. Also, the study showed that D-HGS and NDHGS values of the groups correlate with demographic data, some anthropometric characteristics of upper extremity, and weightlifting performance (apart from age, (right-left arm) UAL and FAL values). Based on these findings, we might express that Olympic style weightlifting sport and specific exercises of this sport correlate with D-HGS and ND-HGS values. Furthermore, the findings of the present study might be useful for future investigations to select weightlifting athletes, to identify talents in Olympic style weightlifting and to develop training program.

\section{Funding}

This project was self-funded. The paper presented orally at the $17^{\text {th }}$. International Sport Sciences Congresss, 13-16 November 2019, Antalya, Turkey.

\section{Conflicts of Interest}

The authors declare no conflict of interest. 


\section{References}

1. Koley S, Yadav MK. An association of hand grip strength with some anthropometric variables in Indian cricket players. Phys Educ Sport, 2009; 7: 113-123.

2. Bassey EJ. Measurement of muscle strength and power. Muscle Nerve, 1997; 5: 44-46. h t t p s:// doi.org/10.1002/( S I C I ) 1097 4598(1997)5+<44::AID-MUS11>3.0.CO;2-Z

3. Nicolay $\mathrm{CW}$, Walker AL. Grip strength and endurance: influences of anthropometric variation, hand dominance, and gender. Inter $J$ Ind Ergon, 2005; 35: 605-618. https://doi.org/10.1016/j.ergon.2005.01.007

4. Schlüssel M M, Dos Anjos LA, De Vasconcellos MTL, Kac G. Reference values of handgrip dynamometry of healthy adults: A population-based study. Clinical Nutrition, 2008; 27(4): 601-607. https://doi.org/10.1016/j.clnu.2008.04.004

5. Fry AC, Ciroslan D, Fry MD, Leroux CD, Schillıng BK, Chıu LZ.Anthropometric and performance variables discriminating elite American junior men weightlifters. Journal of Strength and Conditioning Research, 2006; 20(4): 861-866. https://doi.org/10.1519/00124278-200611000-00023

6. Visnapuu M, Jürimäe T. Handgrip strength and hand dimensions in young handball and basketball players. J Strength Cond Res, 2007; 21(3): 923- 929. https://doi.org/10.1519/00124278-200708000-00045

7. BasseyEJ,HarriesUJ.Normalvaluesinhandgripstrengthin 920 men and women aged over 65 years, and longitudinal changes over 4 years in 620 survivors. Clin. Sci, 1993; 84: 331-337. https://doi.org/10.1042/cs0840331

8. Kallman DA, Plato CC, Tobin JD. The role of muscle strength loss in the age-related decline in grip strength: cross-sectional and longitudinal perspectives. J. Gerontol, 1990;45(3): 82-88. https://doi.org/10.1093/geronj/45.3.m82

9. Mathiowetz V, Kashman N, Volland G, Weber K, Dowe M, Rogers S. Grip and pinch strength: Normative data for adults, Arch Phys Med Rehab, 1985; 66: 69-72.

10.Chatterjee S, Chowdhuri BJ. Comparison of grip strength and isometric endurance between the right and left hands of men and their relationship with age and other physical Parameters. J. Human Ergol, 1991; 20: 41-50.

11.Balogun JA, Akinloye AA, Adenlola SA. Grip strength as a function of age, height, body weight and Quetelet index. Physiotherapy Theory and Practice, 1991; 7(2): 111-119. https://doi.org/10.3109/09593989109106961

12.Hammed AI, Obaseki CO. Interdependence of body mass index with handgrip strength and endurance among apparently healthy teenagers. Turkish Journal of Kinesiology, 2018; 4(1): 1-7.

13.Anakwe RE, Huntley JS, Mceachan JE. Grip strength and forearm circumference in a healthy population. Journal of Hand Surgery (European Volume), 2007; 32(2): 203-209. https://doi.org/10.1016/j.jhsb.2006.11.003

14.Fallahi A, Jadidian A. The effect of hand dimensions, hand shape and some anthropometric characteristics on handgrip strength in male grip athletes and non athletes. Journal of Human Kinetics, 2011; 29(1): 151-159. https://doi.org/10.2478/v10078-011-0049-2

15.Koley S, Yadav M, Sandhu J. Estimation of hand grip strength and its association withsome anthropometric traits in cricketers of Amritsar, Punjab, India. The internet journal of biological anthropology, 2009; 3(1): 7.

16.Zorba E, Ziyagil MA. Body composition and measurement methods, Gen Matbaacllik, 1995; 44(68): 227-235. (in Türkish)

17.Pheasant S. Anthropometry, Ergonomics and the Design of Work. 2nd ed. London: Taylor and Francis; 1996.
18. Otman SA, Demirel H, Sade A. Tedavi Hareketlerinde Temel Değerlendirme Prensipleri [Fundamental Assessment Principles in Treatment Movements]. Ankara, Hacettepe Üniversitesi Fizik Tedavi ve Rehabilitasyon Yayınları [Ankara, Hacettepe University, Physiotherapy and Rehabilitaion Publications]. 1998. (in Turkish).

19.Fess EE. Grip Strength. In: J.S. Casanova (ed.), Clinical assessment recommendations. Chicago: American Society of Hand Therapists, 1992. P. 41-45.

20.Gojanovic B, Waeber B, Gremion G, Liaudet L, Feihl F. Bilateral symmetry of radial pulse in high-level tennis players: implications for the validity of central aortic pulse wave analysis. Journal of Hypertension, 2009; 27(8):1617-1623. https://doi.org/10.1097/hjh.0b013e32832bffc0

21.21. Grant S, Hynes V, Whittaker A, Aitchison T. Anthropometric, strength, endurance and flexibility characteristics of elite and recreational climbers. Journal of Sports Sciences, 1996; 14(4): 301-309. https://doi.org/10.1080/02640419608727715

22.Franchini E, Takito1 MY, Kiss MAPDM, Sterkowicz S. Physical fitness and anthropometrical differences between elite and non-elite judo players. Biology of Sport, 2005; 22(4): 315-318.

23.Sarıtaş N, Hayta Ü, Kaya M. Examination of some physical and physiological findings of male judoka and weightlifters in individual sports. Gaziantep Üniversitesi Spor Bilimleri Dergisi, 2018; 3(4): 200-211.

24.Akkuş H. The relationships between anthropometric characteristics, biomotor abilities, physiological characteristics and success in elite weightlifters [dissertation]. 1994.

25.Singla D, Hussain ME. Association between handgrip strength and back strength in adolescent and adult cricket players. International Journal of Adolescent Medicine and Health, 2018; 0(0). https://doi.org/10.1515/ijamh-2017-0177

26.Gerodimos V. Reliability of handgrip strength test in basketball players. Journal of Human Kinetics, 2012; 31(1): 25-36. https://doi.org/10.2478/v10078-012-0003-y

27.Li K, Hewson DJ, Duchêne J, Hogrel JY. Predicting maximal grip strength using hand circumference. Manual Therapy, 2010; 15(6): 579-585. https://doi.org/10.1016/j.math.2010.06.010

28.Margonato V, Roi GS, Cerizza C, Galdabino GL. Maximal isometric force and muscle cross-sectional area of the forearm in fencers. Journal of Sports Sciences, 1994; 12(6): 567-572. https://doi.org/10.1080/02640419408732207

29. Yıldırım İ, Baş O, Kabadayı M, Taşmektepligil MY, Ocak Y, Karagöz Ş. Examination of the correlation of hand grip strength with upper extremity physical charactercistics in the male players of handball super league. Mustafa Kemal university journal of physical education and sport sciences, 2010; 1(1): 9-15.

30.Lopes J, Grams ST, Silva EF, De Medeiros LA, De Brito CMM, Yamaguti WP. Reference equations for handgrip strength: Normative values in young adult and middleaged subjects. Clinical Nutrition, 2018; 37(3), 914-918. https://doi.org/10.1016/j.clnu.2017.03.018

31. Aydos L, Pepe H, Karakuş H. The research of relative force evaluations in some team and individual sports. Gazi Üniversitesi Kırşehir Ë̆itim Fakültesi, 2004; 5(2): 307-314.

32.Erdağı K, Yargıç MP, Kürklü GP, Aydın L. Accuracy of pinch force sense in elite female adolescent weightlifters. Turkish Journal of Sports Medicine, 2019; 55(x):i vii;2020. https://doi.org/10.5152/tjsm.2020.165 


\section{Information about the authors:}

Kenan Erdağı; (Corresponding Author); Assistant Professor; https://orcid.org/0000-0002-2338-6546; kenanerdal@hotmail. com; Faculty of Education, Necmettin Erbakan University; Konya, 42090, Turkey.

Osman Tüfekçi; Medical doctor; https://orcid.org/0000-0001-5140-3377; uzdrosman@gmail.com; Private Farabi Hospital, Konya, Turkey.

Mustafa Yeşeri; Medical doctor; https://orcid.org/0000-0002-0549-2783; mustafayeseri42@gmail.com; Private Farabi Hospital, Konya, Turkey.

Mehmet F. Yüksel; Assistant Professor; http://orcid.org/0000-0001-6481-5098; yukselmehmetfatih@gmail.com; Faculty of Education, Necmettin Erbakan University; Konya 42090, Turkey.

Nimet Turgut; Research assistant; http://orcid.org/0000-0001-6446-2958; nturgut@selcuk.edu.tr; Selcuk University, Veterinary Faculty, Anatomy Department, Konya, Turkey.

Burak E. Eroğlu; Weightlifting trainer; http://orcid.org/0000-0002-6683-3385; burakertugruleroglu@gmail.com; Youth and Sports Provincial Directorate, Konya, Turkey.

\section{Cite this article as:}

Kenan Erdağı, Osman Tüfekçi, Mustafa Yeşeri, Mehmet F. Yüksel, Nimet Turgut, Burak E. Eroğlu. A study on the determination of handgrip strength of Olympic style weightlifting athletes. Physical Education of Students, 2020;24(3):141-148. https://doi.org/10.15561/20755279.2020.0303

This is an Open Access article distributed under the terms of the Creative Commons Attribution License, which permits unrestricted use, distribution, and reproduction in any medium, provided the original work is properly cited http://creativecommons.org/licenses/by/4.0/deed.en

Received: 12.02 .2020

Accepted: 15.03.2020; Published: 30.06 .2020 